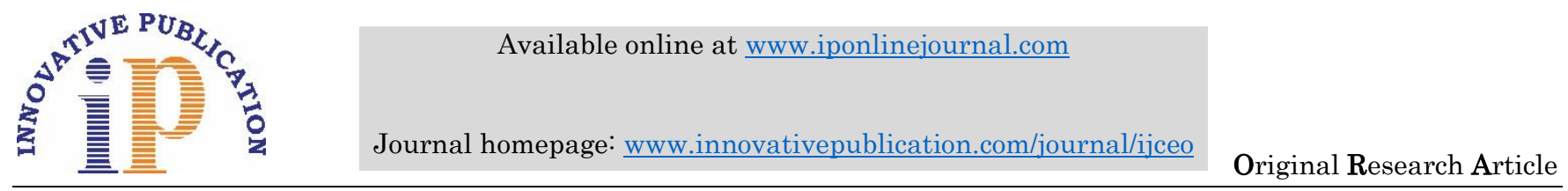

\title{
To compare the intraocular pressure in diabetes mellitus and non diabetics individuals
}

\author{
Shadakshari. S. Math ${ }^{1 *}$, Antariksh. J. Mohta ${ }^{2}$ \\ ${ }^{1}$ Associate Professor, ${ }^{2} \mathrm{III}^{\mathrm{rd}}$ Year Resident, ${ }^{1-3}$ Dept. of Ophthalmology, ${ }^{1-3} \mathrm{D}$. Y. Patil Medical College, Hospital and Research Centre, \\ Maharashtra, India
}

\section{Article Info}

Received: $18^{\text {th }}$ May, 2019

Accepted: $19^{\text {th }}$ June, 2019

Published Online: $9^{\text {th }}$ September, 2019

Keywords: Intraocular pressure, Diabetes, Applanation tonometer, HbA1c.

\begin{abstract}
Introduction: To compare the intraocular pressure in diabetes mellitus patients and non diabetics individuals.

Materials and Methods: A prospective observational type of study with 100 patients, 50 diabetic and 50 non-diabetics subjects, was conducted at D.Y. Patil Medical College and Hospital Kolhapur from $1^{\text {st }}$ February 2019 to $30^{\text {th }}$ April 2019. All subjects underwent routine complete ophthalmological examination, intra ocular pressure was measured using Perkins applanation tonometer. Blood investigation fasting blood sugars, postprandial sugars, and $\mathrm{HbA1c}$ levels was done in diabetics and random blood sugars were done in non diabetic subjects.

Results: The mean intraocular pressure in diabetic subjects was $16.67 \pm 2.04 \mathrm{mmHg}$ and in nondiabetics $13.84 \pm 2.85 \mathrm{mmHg}$ and difference between the two groups was clinically significant $(\mathrm{p}<0.0001)$. The mean intraocular pressure was $(16.88 \pm 3.09 \mathrm{mmHg})$ in diabetic patients with duration of diabetes greater than 10years as compared with $(16.54 \pm 2.76 \mathrm{mmHg})$ in diabetic patients with duration less than 10 years, $\mathrm{p}$ value $>0.05$ which is not statistically significant and with $\mathrm{HbA} 1 \mathrm{c}>6.5 \%$ showed statistically significant higher intraocular pressure compared to $\mathrm{HbA} 1 \mathrm{c}<6.5 \%$.

Conclusion: Diabetic subjects showed higher intraocular pressure as compared to non-diabetic subjects and also there was increase in intraocular pressure with uncontrolled diabetes independent on duration of diabetes. All diabetic patients should undergo intra-ocular pressure measurement routinely.
\end{abstract}

\section{Introduction}

It is estimated the overall prevalence of diabetes in India to be $7 \cdot 3 \% .^{1}$ In many studies diabetes is associated with increase in the thickness of the cornea and also raised intraocular pressure ${ }^{2,3}$ compared to normal healthy individuals.

Glaucoma is caused by raised intra ocular pressure which can cause damage to optic disc by degeneration of retinal ganglion cells $\mathrm{s}^{4,5}$ and their axons and permanent visual field loss. ${ }^{6,7}$ In diabetic patients the intraocular pressure is higher. ${ }^{8}$ Elevated intra ocular pressure and glaucomatous optic neuropathy in diabetes mellitus patients occurs due to small vessels damage which supply the optic nerve head. ${ }^{9}$ Beckers has found elevated intra ocular pressure of more than or equal to $20 \mathrm{mmHg}$ in diabetic individuals. Prevalence of chronic open angle glaucoma is higher in diabetics by factor of about 2 in majority of the population based survey's. ${ }^{10}$ Gold standard for measurement of intra ocular pressure is Goldmann tonometer.

Chronic raised blood sugar levels can lead to major complication like stroke, cardiac failure, renal failure, myocardial infarction also ophthalmological complications. Ophthalmological complication due to diabetes is one of major complication causing low vision or blindness in many patients. Diabetes can cause cataract, retinal blood vessel changes, macular edema, vitreous haemorrhage, diabetic retinopathy. ${ }^{11}$

\section{Aims}

To compare intraocular pressure in Diabetes mellitus patients and Non diabetics individuals.

\section{Objective}

1. To compare intra ocular pressure between Diabetes mellitus patients and Non diabetics.

2. To compare intra-ocular pressure in Diabetes mellitus patients with $\mathrm{HbA} 1 \mathrm{c}$ value of $>6.5 \%$ and those with $\mathrm{HbA} 1 \mathrm{c}$ value of $<6.5 \%$.

3. To find out intra ocular pressure in relation to duration and different stages of diabetic retinopathy (ETDRS Classification).

\section{Materials and Methods General Design}

This is a hospital based prospective observational study. Patients having diabetes mellitus (who are previously

\footnotetext{
*Corresponding Author: Shadakshari. S. Math, Associate Professor, Dept. of Ophthalmology, D.Y. Patil Medical College, Hospital and
} Research Centre, Maharashtra, India 
diagnosed by physician) on treatment and Non diabetic individuals will be included in our study. Two groups will be formed which includes Group A constituting diabetes mellitus patients and Group B constitutes Non diabetic individuals.

Detailed history of diabetes mellitus patient will be taken regarding duration of diabetes, treatment, fasting, post prandial blood sugar levels and HbA1c will be recorded.

All the patients of Group A and Group B will undergo complete ophthalmic examination, which includes best corrected visual acuity, slit lamp anterior segment examination, slit lamp biomicroscopy (+90D)/ indirect ophthalmoscopy for posterior segment examination, Perkins applanation tonometry to measure intra ocular pressure. Gonioscopy will be done if required. For posterior segment examination pupils will be dilated using mydriatics and slit lamp biomicroscopic/ indirect ophthalmoscopy examination will be done to find out the diabetic retinopathy changes and will be classified according to the ETDRS classification. Intra ocular pressure will be compared between Group A and Group B, to correlate intra ocular pressure in relation to duration of diabetes mellitus and different stages of diabetic retinopathy. Diabetic retinopathy changes will be classified according to the ETDRS classification (Non proliferative and proliferative diabetic retinopathy).

\section{Inclusion Criteria}

1. Patients with diabetes mellitus.

2. Age group20-70 years.

3. Non diabetic individuals.
1. Diabetes Mellitus with hypertension, thyroid disorder and other systemic diseases.

2. Patients having glaucoma.

3. Patients having corneal pathology and any other ocular abnormalities like pterygium, entropionj, trichiasis.

4. Patients who have undergone previous ocular surgeries.

5. Contact lens wearers.

6. Patients on topical and systemic steroids.

7. Patients having refractive error greater than $\pm 6 \mathrm{D}$ spherical or cylinder greater than $\pm 3 \mathrm{D}$.

8. Pregnant women.

9. Patients who are daily smokers.

10. Non-diabetic individuals with ocular or systemic disease which influences intra-ocular pressure.

\section{Sample Size}

Group A: 50 Diabetes mellites patients.

Group B: 50 Non diabetic individuals.

\section{Results}

100 patients were included in our study. 47 patients had Type 2 diabetes mellitus (all were non insulin dependent) and 3 patients had Type 1 diabetes mellitus (all were insulin dependent), and 50 patients were Non-diabetics subjects. Mean age of non diabetics was $56.8 \pm 10.2$ years and that of diabetics $58.30 \pm 9.97$ years ( $p$ valve 0.43 ) statistically not significant. In those 50 diabetic patients 33 were male and 17 were female. Mean age of male subjects was 59.36 \pm 9.0 years and that of female was $56.47 \pm 11.28$ years in diabetic group which was no statistically significant (p value 0.37 ).

\section{Exclusion Criteria}

Table 1

\begin{tabular}{|c|c|c|c|c|}
\hline Patients & n & Mean IOP(mmHg) & SD & p-value \\
\hline Diabetics & 50 & 16.67 & 2.04 & \multirow{2}{*}{ P $<0.0001^{*}$} \\
\hline Non Diabetics & 50 & 13.84 & 2.85 & \\
\hline
\end{tabular}

Table 1 shows mean intra-ocular pressure higher $(16.67 \pm 2.04 \mathrm{mmHg})$ in diabetic patients as compared with $(13.84 \pm 2.85 \mathrm{mmHg})$ in non-diabetic, $\mathrm{p}$ value $<0.0001$ which is statistically significant.

Table 2

\begin{tabular}{|c|c|c|c|}
\hline Duration of diabetes & Mean IOP $(\mathrm{mmHg})$ & SD & p-value \\
\hline$<10$ years & 16.09 & 3.6 & P $<0.35$ \\
\hline
\end{tabular}

Table 2 shows mean intra ocular pressure was $(16.88 \pm 3.09 \mathrm{mmHg})$ in diabetic patients with duration greater than 10 years as compared with $(16.54 \pm 2.76 \mathrm{mmHg})$ in diabetic patients with duration less than 10 years, $\mathrm{p}$ value $>0.05$ which is not significant.

Table 3

\begin{tabular}{|c|c|c|c|}
\hline HbA1c & Mean IOP & $\mathbf{\pm S D}$ & p-value \\
\hline$<6.5$ & 15.33 & 1.55 & $<0.0005^{*}$ \\
\hline$>6.5$ & 16.85 & 2.94 & \\
\hline
\end{tabular}

Table 3 shows mean intra-ocular pressure higher in diabetic patients with HbA1c value $>6.5 \%$ as compared with diabetic patients with $\mathrm{HbA} 1 \mathrm{c}$ value $<6.5 \%$, p value $<0.0005$ which is statistically significant. 
Table 4

\begin{tabular}{|c|c|c|c|}
\hline Diabetic Retinopathy & Mean IOP & $\mathbf{\pm S D}$ & p-value \\
\hline NPDR & 18.7 & 2.14 & $<0.0001^{*}$ \\
\hline PDR & 13.1 & 1.21 & \\
\hline
\end{tabular}

Table 4 shows mean intraocular pressure lower in patients who have proliferative diabetic retinopathy than in those patients having non-proliferative diabetic retinopathy, $p$ value $<0.0001$ which is statistically significant.

\section{Discussion}

Our study shows mean intraocular pressure higher $(16.67 \pm 2.04 \mathrm{mmHg})$ in diabetic patients as compared with $(13.84 \pm 2.85 \mathrm{mmHg})$ in non-diabetic, $p$ value $<0.0001$ which is statistically significant. Study conducted by Jain and Luthra, reported that mean intraocular pressure in diabetic eyes is slightly higher than nondiabetic eyes. ${ }^{12}$ Contrary to our study, study conducted by Tielsch JM, Katz J et al Baltimore eye survey could not show any positive corelation between diabetes and elevated intra ocular pressure(POAG) as compared to non diabetic individuals. ${ }^{13}$

In our study it was observed that mean intraocular pressure higher in diabetic patients with $\mathrm{HbA1c}$ value $>6.5 \%$ as compared with diabetic patients with HbA1c value $<6.5 \%, \mathrm{p}$ value $<0.0001$ which is statistically significant.

A study conducted by Oshitari T., Fujimoto $\mathrm{N}$ et al showed higher intraocular pressure with chronic hyperglycaemia i.e $>6.5 \% .{ }^{14}$ Baisakhiya S, Garg P et al also had similar finding, mean IOP of diabetic subjects with $\mathrm{HBA} 1 \mathrm{C}<7 \%$ was $16.9 \pm 0.43 \mathrm{~mm} \mathrm{Hg}$ and with $\mathrm{HBA} 1 \mathrm{C}>8 \%$ was $18.62 \pm 0.22 \mathrm{~mm}$ of $\mathrm{Hg} \quad(P<0.005)$ which was significantly higher. ${ }^{15}$

In our study the mean intraocular pressure was lower in patients who had proliferative diabetic retinopathy than in those patients having non-proliferative diabetic retinopathy, $\mathrm{p}$ value $<0.0001$ which is statistically significant. Study conducted by Cristiansson (1961) also reported low IOP in proliferative retinopathy compared to non-proliferative retinopathy. ${ }^{16}$ On the contrary one of the study conducted by Masato Matsuoka, Nahoko Ogata et al showed IOP in each diabetic retinopathy group was significantly higher than that in their nondiabetic group $(P<0.001)$, but there was no significant difference between the diabetic retinopathy groups. ${ }^{*} P<0.001 .{ }^{17}$

\section{Conclusion}

Our study showed that mean intra ocular pressure was higher in diabetic group as compared to non diabetic group. Mean intra ocular pressure was higher in uncontrolled diabetic patients (HbA1c >6.5) when compared with controlled diabetic patients $(\mathrm{HbA} 1 \mathrm{c}<6.5)$ and we also noted that mean intra ocular pressure did not differ with the duration of diabetes mellites.

Majority of the subjects in our study were on oral hypoglycaemics drugs diagnosed as type 2 diabetes mellitus and only 3 subjects were insulin dependent diagnosed as type 1 diabetes mellites so further studies are needed to evaluate intraocular pressure among type 1 insulin dependent type 1 diabetes mellites. For all diabetic patents should undergo intraocular pressure measurement routinely, long term follow-up of these patients is required to know the conversion to chronic open angle glaucoma.

\section{Source of Funding: None.}

\section{Conflict of Interest: None.}

\section{References}

1. Lancet Diabetes Endocrinol 2017 Published Online June 7, 2017 http://dx.doi.org/10.1016/ S2213-8587(17)30174-2.

2. Becker B. Diabetes mellitus and primary open angle glaucoma. The XXVII Edward Jackson Memorial Lecture. Am J Ophthalmol 1971;71(1 Pt 1):1-16.

3. John DE, Josie MME, Danny AR, Glaucoma incidence in an unselected cohort of diabetic patients: is diabetes mellitus a risk factor for glaucoma? DARTS/MEMO collaboration. Diabetes Audit and Research in Tayside Study. Med Monitoring Unit. Br J Ophthalmol 2000;84(11):1218-24.

4. M. A. Kass, D. K. Heuer, E. J. Higginbotham, "The Ocular Hypertension Treatment Study: a randomized trial determines that topical ocular hypotensive medication delays or prevents the onset of primary open-angle glaucoma," Arch Ophthalmol 2002;120(6):701-13.

5. A. Sommer, J. M. Tielsch, J. Katz, "Relationship between intraocular pressure and primary open angle glaucoma among white and black Americans: the Baltimore eye survey," Arch Ophthalmol 1991;109(8):1090-95.

6. Javitt JC, Aiello LP. Cost effectiveness of detecting and treating diabetic retinopathy. Ann Int Med 1995;124(1 Pt2):164-9.

7. Nakamura M, Kanamori A, Negi A. Diabetes mellitus as a risk factor for glaucomatous optic neuropathy. Ophthalmologica 2005;219(1):1-10.

8. Sahin A, BayerA, Go "khan O"zge. Corneal Biomechanical Changes in Diabetes mellitus and their influence on intraocular pressure measurements. Invest Ophthalmol Vis Sci. 2009;50:4597-4604.

9. Safir, A.; Paulson. E. P.; Klaynmu, J., and Cerstenfeld, J.: Ocular abuornla litics in juvenile diabetics. Arch Oph (Chicago), 1966;76;557.

10. Klein BE, Klein R, Jensen SC. Open-angle glaucoma and older-onset diabetes. The Beaver Dam Study. Ophthalmol 1994;101(7):1173-7

11. Fong DS, Aiello LP, Ferris FL, et al. Diabetic retinopathy. Diabetes Care 2004;27(10):2540-53.

12. Jain, IS. and Lnthra, CL.: Diabetic retinopathy, its relationship with in traocular pressure. Arch Oph (Chica go) 1967;78:198.

13. Tielsch JM, Katz J, Quigley HA, Javitt JC, Sommer A. Diabetes, Intraocular Pressure, and Primary Open-angle Glaucoma in the Baltimore Eye Survey. Ophthalmol, 1995;102(1):48-53.

14. Oshitari T, Fujimoto N, Hanawa K, Adachi-Usami E. Effect of Chronic Hyperglycemia on Intraocular Pressure in Patients With Diabetes. Am J Ophthalmol, 2007;143(2):363-5.

15. Baisakhiya S, Garg P, Singh S. Association between glycemic control and intraocular pressure in patients of Type II diabetes mellitus. Natl J Physiol Pharm Pharmacol 2017;7(1):43-6. 
16. Cristiansson, J., Intraocular pressure in diabetes mellitus, Acta. Ophthalmol 1961;39:159.

17. Matsuoka M, Ogata N, Matsuyama K, Yoshikawa T,

Takahashi K. Intraocular pressure in Japanese diabetic patients. Clin Ophthalmol. 2012;6:1005-9.

doi:10.2147/OPTH.S33131

How to cite this article: Math SS, Mohta AJ. To compare the intraocular pressure in diabeties mellitus and non diabetics individuals. Indian $J$ Clin Exp Ophthalmol. 2019;5(3):301-4. 